\title{
Genetic and Molecular Research of Resistance to Wilt in Cotton: A Concise Review
}

\author{
Aman Deep Ranga ${ }^{1 *}$, Vasudha Kak ${ }^{2}$ and Mayur S. Darvhankar ${ }^{3}$ \\ ${ }^{1}$ Department of Vegetable Science, Dr. Yashwant Singh Parmar University of Horticulture \\ and Forestry, Nauni, Solan, Himachal Pradesh, 173230, India \\ ${ }^{2}$ Division of Agricultural Extension, Indian Agricultural Research Institute, \\ New Delhi-110012, India \\ ${ }^{3}$ Department of Genetics and Plant Breeding, School of Agriculture, Lovely Professional \\ University, Phagwara, Punjab-144411, India \\ *Corresponding author
}

\section{A B S T R A C T}

\begin{tabular}{|l|}
\hline Ke y w or d $\mathbf{s}$ \\
Fusarium wilt, \\
$\begin{array}{l}\text { Gossypium spp., } \\
\text { Helicoverpa } \\
\text { armigera, } \\
\text { Verticillium wilt }\end{array}$ \\
\hline Article Info \\
\hline $\begin{array}{l}\text { Accepted: } \\
18 \text { May } 2020 \\
\text { Available Online: } \\
\text { 10 June } 2020\end{array}$ \\
\hline \hline
\end{tabular}

One of the key natural fiber of the world is Cotton (Gossypium spp.), a member of Malvaceae family. Fusarium wilt (FW) is majorly caused by the Fusarium oxysporum f. sp. vasinfectum (FOV) which is a soil-borne fungus that leads to Verticillium Wilt. It is one of the most serious diseases in cotton, has a deterioting influence on crop's production and quality. Helicoverpa armigera, known as the cotton bollworm, has been controlled over the last few years, Verticillium Wilt (VW) has become a key restriction in production of cotton. DNA molecular markers are widely used for establishing genetic and physical genome maps, differentiating individuals, investigating genetic relatedness, and studying genome organisation of a large population with accuracy. The wilt had become a matter of research in cotton-resistance hereditary qualities, rearing and plant pathology. This work is consists of a literature review that is eventually providing a complete union of research progress in plant breeding, hereditary qualities and molecular mapping of the cotton genome with molecular markers for identification of fusarium wilt. Enrolment of Fusarium wilt resistant cultivars has demonstrated to be the most economically worthy method to control the disease. It is expected that new plant breeding methods and new varieties/hybrids resistant to Verticillium wilt will be developed in no time which can combat Fusarium Wilt.

\section{Introduction}

Cotton crop outputs are the major natural fiber in the world and as well as oilseed crops (Constable and Bange, 2015). While cotton is mostly grown in 80 countries, India leads in cotton production followed by China, United
States, Pakistan and Brazil (Khan et al., 2020). Malvaceae family includes Gossypium species which comprises of 90 genera, including the genus Gossypium. Species of this genus shows development of bushes and saplings up to seven feet tall with an inclination of whole leaves rotating with 
stipules. Gossypium hirsutum and Gossypium barbadense are exemplary allopolyploids that risen up out of the mix of two earlier separated diploid genomes, containing one genome identified with those found in the Old World (A-genome diploids) and a subsequent genome identified with those of the New World (D-genome diploids) (Zhao et al., 1998).There are 46 diploid and 7 tetraploid cotton species after molecular affirmations and taxonomy indicated two new tetraploid ones, viz., Gossypium ekmanianum (AD6) and Gossypium stephensii (AD7) (Gallagher, 2017; Grover, 2015). Among these, solitary four are cultivated all around the globe: two species of diploids $(2 \mathrm{n}=2 \mathrm{x}=26)$ and two of allotetraploids $(2 n=4 x=52)$. Global cotton production is manifested from the two allotetraploid species Gossypium hirsutum and Gossypium barbadense (Wendel, 1992, 2013; Wang, 2015).

During the growth of cotton, it is prone to diseases like Fusarium wilt (FW) and Verticillium wilt (VW) which can show severity at some stage. These diseases tend to make the harvest yellow, shrink and fall, it can likewise harm the vascular tissue and at last can cause death of the plant. So consequently, they are likewise called as the 'cancer' of cotton crops (Zhang et al., 2018).

In past few years, critical epidemics of cotton Verticillium wilt have happened for various reasons, for example, the worldwide changes in the atmosphere and environment, the longterm uninterrupted cropping of cotton and the frequent introduction of new cotton varieties/hybrids from different regions (Guo et al., 2015). It is one of the vital soil-borne disease with a wide scope of hosts (Sal'kova et al., 1965). The variation and divergence of Verticillium dahliae strains have headed towards the shortage of resistant cotton cultivars. From 2009 to 2010, China (5.0-6.6 million acres) was influenced by Verticillium wilt disease in more than $50 \%$ of the cotton growing region (National Cotton Council of America - Disease Database; Zhang et al., 2013).

To determine genetic diversity, DNA based markers which includes restriction fragment length polymorphisms (RFLPs) (Ashokkumar, 2011), random amplified polymorphic DNA (RAPD) (Zhang, 2005; Shen, 2007; Pang, 2009), amplified fragment length polymorphisms (AFLPs) (Rakshit, 2010), simple sequence repeat (SSR) (Freire, 2008; Song, 2009; Liang, 2013), expressed sequence tags (ESTs) (Wang, 2013), intersimple sequence repeat (ISSR) (Cao, 2014), and single nucleotide polymorphisms (SNP) are used (Majeed et al., 2019). While comparing with other biomarkers, SSR has additional benefits which include codominant inheritance, more reproducibility, distribution all over the genome and it is highly informative, reliable, transferable (Ditta et al., 2018).

Several quantitative trait loci (QTL) linked to Verticillium wilt disease have been labelled utilizing family-based QTL mapping strategies by gathering isolating populations of two cotton cultivars having distinction in Verticillium wilt resistance (Bolek et al., 2005; Yang et al., 2008; Wang et al., 2008; Jiang et al., 2009; Ning et al., 2013; Fang et al., 2013; Li et al., 2013; Zhang et al., 2014; Zhang et al., 2014) and by association mapping techniques (Zhao et al., 2014).

Fusarium wilt is presently not, at this point one of the significant diseases in cotton in the United States of America (USA) since the 1980s (Blasingame and Patel, 2013) and in China since 1990s (Jian et al., 2003, Shen and Chen, 1982; Tan, 1982; Ma and Jian, 1994). However, Fusarium oxysporum f.sp. vasinfectum (FOV) race 4 in California since the 2000s and a harmful strain in Australia 
since the mid 1990s have created as one of the significant dangers to cotton production (Allen, 2007; Colyer, 2007; Kirkby et al., 2013). Fusarium wilt can go under control, mostly because of human endeavors, while controlling Verticillium wither, particularly the defoliating type, has become progressively more compelling following by the management of bollworm in Bt cotton in last couple of years. Scarcity of resistant cotton plants have been caused due to the variation and differentiation of Verticillium dahliae strains (Wan et al., 2012).

Genetic diversity in various plant species plays a fundamental part of crop production in farming, including cotton. Variability in genes in the Gossypium species is available all around the globe, covering enormous geographic and natural specialities. It is an imperative wellspring of conserved genetic diversity in situ in Mexico for cotton origin (Gutiérrez, 2009; Myers, 2009) and is safe guarded ex situ inside overall cotton germplasm assortments and materials of breeding programs.

\section{Mapping of wilt resistance quantitative trait loci and related genes}

A quantitative trait locus is basically a segment of DNA that associates with a variation of a quantitative trait in the phenotype of a population (Miles and Wayne, 2008). These are mapped by using molecular markers (such as SSRs and AFLPs) which correlates with an observed trait. The stability of QTL and its advance use in breeding: QTL mapping is basically for marker-assisted selection (Cobb et al., 2019). In this review, major QTLS related to wilt in both field as well as protected cultivation were acknowledged. It should be noted that this review just indicates the effectiveness of QTL in both resistive and susceptible genotypes. In view of QTL mapping, Marker assisted selection uses gyrated markers on both the sides which were then joined with phenotype screening in an enormous population, recommended to improve selection proficiency for crop improvement purpose (Collard and Mackill, 2008).

Bolek et al., (2005) mapped F2 population obtained from highly tolerant Pima S-7 and susceptible Acala 44 and used microsatellites to uncover polymorphism among susceptible and resistant parents. 225 SSRs marker pairs screened bulk comprised by 10 each resistant and susceptible progeny. 60 markers were utilized to break down QTLs and 11 linkage groups were built using 35 markers and spreading over to $531 \mathrm{cM}$ with a mean distance of $15.17 \mathrm{cM}$. They found that 15 markers have huge linkage affiliation and nine were conveyed to chromosomes 10,11 , 12 and 25. 3147-2, CM12 and STS1 loci had a major effect on verticillium wilt resistance. On chromosome 11, LG-1 had two loci while LG-2 had one.

Wang et al., (2009) found fusarium wilt resistant gene using molecular mapping firmly linked to the SSR marker "JESPR304280" on chromosome D3(c17) and named it as FWR. Four QTLs for fusarium wilt resistance were also detected viz., CHR.A79c7), D3, D9(c23) and D1(c15). One significant QTL (LOD>20) was found near marker JESPR304 within a short period of $0.06-0.2 \mathrm{cM}$ and portrayed $52.5-60.9 \%$ of total phenotypic variation. The trial affirmed the nearness of a significant quality in Chr.D3 and it was the absolute first report of molecular mapping accomplished for resistance to fusarium wilt in cotton.

Ulloa et al., (2011) evaluated F2 and RILs of interspecific populations of Pima-S7 and Upland TM-1 respectively and QTL mapping indicated inheritance and interaction of nine cotton chromosomes while major QTLs were 
distinguished on five chromosomes viz., Fov1-C06, Fov1-C19, Fov1-C08, Fov1-C16 and (Fov1-C111 and Fov1-C112) loci and explained $8-31 \%$ phenotypic variation. Fov1$\mathrm{C} 16$ loci in F2 populations and RILs assumed a key job in presenting FOV race 1 resistance.

Wilsom et al., (2012) evaluated genetic base of MCU-5 which is resistant to FW and found three QTLs in F3 and eight in F4 which clarified $9-41 \%$ of phenotypic variation. These were situated on four linkage groups including A6 (Chr 6), D6 (Chr 25) and $\mathrm{D} 4(\mathrm{Chr} 22)$ with two QTL situated in a comparable region as found in Sea Island Cultivar Pima 3-79 which is FW resistant.

Ullo et al., (2013) observed a unique resistance gene (Fov 4) template in F2 populations of $G$. hirsutum x $G$. hirsutum $L$., $G$. hirsutum $\mathrm{x} G$. barbadense and $G$. barbadense x $G$. barbadense $L$. based on inheritance of phenotypes. The FOV4 gene was found to be situated close to genomic region of chromosome 14 labelled as QTL FOV4-C141 and it contributed maximum to FOV race 4 resistance produced in $\mathrm{F} 2$ progeny. Additionally recognized a lot of 11 SSR markers which showed the contribution of quality and quality connection between six linkage chromosomes viz., 3, 6, 8, 14 and 25 in legacy of FOV race 4 resistance. QTLs with minor impacts portrayed the $5-19 \%$ variety.

Zhang et al., (2014) utilized interspecific chromosome fragment introgression lines to recognize QTLs linked with verticillium wilt in cotton and vaccinated with three defoliating $V$. dahliae strains. 42 QTLs comprising of 23 with increasing resistance and 19 with diminishing affected host resistance in contrary to three strains. 18 chromosomes were identified for mapping of these QTLs viz., A1, A3, A4, A5, A7, A8, A9, A12, A13, D1, D2, D3, D4, D5, D7, D8,
D11 and D,12 having LOD value from 39.29.

Zhang et al., (2015) mapped 10 resistance QTLs in backcross inbred lines for verticillium wilt dependent on $2895 \mathrm{cM}$ linkage map with 392 SSR markers. Genetic diversity of VW resistance in cotton was likewise concentrated in 4 year replicated trial and ten VW resistance QTLs were identified. Out of 306 QTLs and linked SSR markers, 28 disease resistance QTL clusters and 24 hotspots were determined and estimated information for MAS and high resolution mapping of resistant QTLs and genes.

Zhang et al., (2015) detected approximately 40 QTLs on 19 chromosomes in five FW resistant sources of USA viz., Dillon, Dixie Triumph, Cook 307-6, Wild and Coker Clevewilt and three from China viz., Chuan 52-128, Chuan 57-681 and CRI 12. Zhao et al., (2014) evaluated 150 elite G. hirsutum L. germplasm from around the world for markerassisted selection of verticillium wilt resistance in cotton. They identified 42 QTLs with verticillium wilt resistance by association mapping which was scattered among 15 chromosomes. 10 QTLs were previously identified and 32 were new unreported. QTL clusters for VW resistance were also proved on chromosome 16 in this study.

Xiu-hua et al., (2016) used 13 microsatellites markers flanking QTLs and developed 155 cotton inbred lines through pyramiding diverse QTLs identified with verticillium wilt resistance from generations obtained by crossing 5026 and 60182. They identified four superior QTLs viz., q-13?NAU6598-1, q6/NAU2754-2, q-5/NAU905-2 and q8/NAU3053-1 respectively.

Palanga et al., (2017) reported 119 QTLs of disease incidence and disease index on 25 
chromosomes of cotton genome with the exception of chromosome 13 (c13). For disease index, 62 QTLs explained 3.7-12.2\% phenotypic variation were found on 24 chromosomes with the exception of $\mathrm{c} 11$ and c13. Seven QTLs were found stable at all situations among which six have sGK9708 allele. For disease incidence, 59 QTLs explained 2.3-21.30\% of phenotypic variation were found on 19 chromosomes except $\mathrm{c} 5, \mathrm{c} 8$, c12-c13, c18-c19 and c26. 28 QTLs were steady in all environments. On chromosome 13, 18 QTL clusters consists of 40 QTLs were categorized viz., c1-c4, c6-c7, c10, c14, c17, c20-c22 and c24-c25.

Wang et al., (2018) detected qVWR-16-1a between two markers viz., BNL2986 and NAU751 on chromosome 16 with $5.73 \mathrm{cM}$ and accounted for $16.53 \%$ of phenotypic variation and resistance in $\mathrm{F} 2$ and $\mathrm{F} 2: 3$ populations of $G$. hirsutam x Luyuan 343 introgressed from $G$. barbadense L. qVWR$16-1 \mathrm{~b}$ was located on the same interval towards qVWR-16-1a with a distance of 1.73 $\mathrm{cM}$ to locus NAU751 and explained for $10.27 \%$ phenotypic variation. qVWR-16-2b is situated on another stretch somewhere in the range of BNL1604 and BNL1395 on the same chromosome fragment with $1.39 \mathrm{cM}$ to BNL1395 and accounted for $10.8 \%$ phenotypic variation. qVWR-2-1b was located somewhere in the range of BNL3950 and BNL3971 with $0.01 \mathrm{cM}$ to BNL3950 on chromosome 2 and accounted for $13.78 \%$ of phenotypic variation. Subsequently, gene pyramiding the resistant genotypes of marker BNL1395 and NAU751 can enhance VW resistance.

Marker assisted selection for wilt
resistance in cotton

\section{Simple sequence repeat (SSR)}

These were established by Litt and Luty
(1989) and by Edwards et al., (1991) firstly in humans and they were lately employed to plants by Akkaya et al., (1992). They are also known as "microsatellites" and has a major potential to be utilized as a flexible device in molecular breeding because of their property and capability for predicting variation among cultivars. (Adato et al., 1995; Levi and Rowland, 1997).

Zhen et al., (2005) and colleagues mentioned that the distance between a locus linked to Verticillium wilt resistance and the SSR marker BNL3556 is $13.1 \mathrm{~cm}$ which represented for $50.1 \%$ of phenotypic variance in $175 \mathrm{~F}_{2}$ individuals obtained from a cross of G. barbadense $(\alpha 15-3493) \times G$. hirsutum (Shihezi875). The DNA of 10 each resistant and susceptible individuals were then enhanced \& utilized to create resistant and susceptible genetic stocks which were screened with 768 pairs of SSR primers in which BNL2440 and BNL3255 both exhibited polymorphisms among resistant and susceptible DNA pools. BNL3255 primer amplified a fragment of 208bp which was named as BNL3255-208. BNL3255-208 and the verticillium wilt resistance locus has a genetic distance of $13.7 \mathrm{cM}$.

Du et al., (2006) determined 510 lines out of which 155 cotton introgressed lines from interspecific hybridization were detected and results predicted specific SSR locus among interspecific lines with diverse exotic gene sources and the more specific loci with exotic genes the more resistance to verticillium wilt.

Wang et al., (2007) evaluated 95 upland cotton genotypes and used 19 SSR primers and the results predicted that 19 SSR primers created 89 DNA bands in which 61 were observed polymorphic. The absolute number of genes per locus ranged from 3-8 with an average of 4.7. The polymorphic information content an incentive for SSR amplification 
varied from 0.978-0.998 with an average of 0.69 .

\section{Amplified fragment length polymorphism (AFLP)}

These are polymerase chain reaction (PCR) based markers which are like to randomly amplified polymorphic DNA (RAPD) and restriction fragment length polymorphisms (RFLP) analysis which can be carried out on genomes of any cultivar and complexity. It is widespread and a multilocus marker and basically requires PCR amplification of restriction fragments of total double-digested genomic DNA (Katherine Reyes and Marcus Zervos, Molecular Diagnostics, 2010)

Qi et al., (2000) evaluated cotton and revealed on susceptible and four resistance related DNA fragments of 200-525 bp length. Set of two primers were used to enhance DNA fragments and acquired two bands viz., resistive (292 bp) and susceptive (410 bp) and the distance between them was $13.49 \mathrm{cM}$ whereas distance among resistance gene marker and resistance gene was $20.947 \mathrm{cM}$.

Zhu et al., (2001) studied upland cotton and applied AFLP markers for selection in verticillium wilt and found the distance amidst resistance gene and resistance gene marker was $9.29 \mathrm{cM}$.

Abd-Elaslamet et al., (2002) stated that AFLP method ustilizing silver staining to illustrate the bands is successful as applied to the molecular portrayal of Fusarium spp. what's more, had a solid connection between AFLP gatherings and morphological characters.

Wang and Roberts (2006) evaluated interspecific crosses of Pima S-7 x Acala NemX and Pima S-7 x Acala SJ-2 and determined that significant gene (named as Fov1) with allele dosage impact affirmed resistance from Fusarium oxysporum f.sp. Vasinfectum race 1 in Pima S-7. Two AFLP were linked to Fov1 with a distance of 9.3 and $14.6 \mathrm{cM}$ from gene. Exceptionally resistant plants of F2 and F3 of Pima S-7 x NemX specified transgressive isolation impacts of minor genes in NemX pooled with Fov1 from Pima S-7.

Wang et al., (2007) studied 95 upland cotton genotypes and used 20 EcoRI-MseI AFLP markers and the results which came out was 1480 major bands were observed. And 214 polymorphic bands. 47-109 bands per primer with an average of 74 were observed. The polymorphic information content value for AFLP amplification varied from 0.01-0.24 with an average of 0.09 .

\section{Single nucleotide polymorphisms (SNPs)}

These are the broadest type of genetic variation among living beings. Each SNP speaks to a variation in individual DNA block called nucleotide. These also act as biological markers and play a major role in locating genes associated with diseases. They also play a major role when they are present within a gene or a genomic region by manipulating gene function.

Cai et al., (2009) composed a haplotype map of 299 cotton germplasms and generated 1297 million reads ( $125 \mathrm{bp}$ ) comprising of 324.19 $\mathrm{Gb}$ of cotton genomic DNA sequence using SLAF-seq method. 649625 SLAFs were estimated and used to call SNPs had a normal profundity of 5.97 overlap per individual, 884799 SNPs have minor allele frequency (MAF) of $<5 \%$ while the remaining 85630 SNPs have MAF $\geq 0.05$ and the missing rate was $\leq 50 \%$. Distance between two genomic tags was $29.2 \mathrm{~kb}$ and a set of 85630 SNPs covered all the 26 chromosomes. Chromosome A08 (8764 SNPs) had the largest number of SNPs followed by A06 
(6295 SNPs) and the chromosome D04 (879 SNPs) has the most modest number of SNPs.

Li et al., (2017) examined 299 accessions and detected 85630 SNPs using a particular locus amplified fragment sequencing technique. They distinguished a sum of 17 noteworthy SNPs at $\mathrm{P}<1.17910-5 \quad(\mathrm{P}=1 / 85630$, $\log 10 \mathrm{P}=4.93)$. Haplotype structure assessment anticipated 22 candidate traits for verticillium wilt resistance based on A10_99672586 with a minimum P-value $(-\log 10 \mathrm{P}=6.21) . \quad \mathrm{CG} 02$ was close to SNP A10_99672586 (0.26 Mb) situated in a $372 \mathrm{~kb}$ haplotype square and its Arabidopsis AT3G25510 homologues contain TIR-NBS-LRR domain which may be engaged with disease resistance. Rt-PCR and virus-induced gene silencing (VIGS) portrayed that $\mathrm{CG02}$ was explicit in resistant genotype, Zhongzhimian2 (ZZM2), therefore, it indicates that CG02 is an aspirant gene for resistance against $V$. dahlia in cotton.

Li et al., (2017) used a board of 299 accessions of upland cotton and trait SNP association detected 17 major SNPs at $\mathrm{P}<1.17$ $\mathrm{x} 10-5 \quad(\mathrm{P}=1 / 85630,-\log 10 \mathrm{P}=4.93)$. They predicted 22 candidate genes for verticillium wilt resistance dependent on A10_99672586 with $\mathrm{P}>-\log 10 \mathrm{P}=6.21$.

\section{Random amplified polymorphic DNA (RAPD)}

These are DNA segments which are enhanced by PCR with the help of short synthetic primers usually of $10 \mathrm{bp}$ in size of any random or irregular sequence. These oligonucleotides have the tendency to operate as both forward and reverse primer and are additionally ready to amplify segments of 110 genomic sites at same time (Hadrys et al., 1992).

Fang et al., (2001) obtained a RAPD marker with OPB-191300 connected with wilt resistance in cotton and found genetic distance to be $12.4 \mathrm{cM}$ with $12.1 \%$ variation.

Zhang et al., (2002) amplified the DNA of 58 glandless cotton varieties using 15 diverse primers. 50 bands $(47.20 \%)$ were polymorphic out of 106 RAPD identified bands, thus, varieties were classified into six groups.

\section{Sequence tagged sites (STS)}

These are short DNA fragmenrs of size $200-$ $500 \mathrm{bp}$ which have a solitary occurrence in genome whose base sequence and locus is known (Olson et al., 1989).

Fang et al., (2013) designed a total of 72 primers using 36 unique RGA-AFLP sequences which resulted in formation of only one polymorphic STS marker. In BILs population, 7 primers were used and the polymorphism ratio ranged between 11.1 $82.6 \%$ with an average of $31.1 \&$ whereas in RILs, 8 primers were informative and polymorphism ratio ranged between 9.1 $89.3 \%$ with an average of $18 \%$.

Wilting in cotton is turning into a significant zone of research in cotton resistance genetics, molecular breeding and plant pathology. Employments of markers have added helpful data to the comprehension of the genetic base of Verticillium Wilt resistance in cotton. With the distinguish understanding of many potential DNA markers in plant breeding, researchers implemented capability using Marker Development. In plant breeding, marker assisted selection is being used as a molecular tool for the utilization of DNA markers associated with agronomical important genes and other genes linked with biotic and abiotic stress resistances by selecting phenotype using genotype markers. The utilization of the molecular marker innovation in plant breeding unwrapped new 
ways for crop improvement is known as molecular breeding. This review thus helps in investigating the ongoing research exploration on molecular breeding strategies for resistance and molecular markers.

\section{Conflicts of Interest}

The authors declare no conflict of interest.

\section{References}

Allen, S.J. (2007). Integrated disease management for Fusarium wilt of cotton in Australia. Proc. World Cotton Research Conference 4, Lubbock, Texas, USA,. International Cotton Advisory Committee (ICAC), Washington DC.

Ashokkumar, K. and Ravikesavan, R. (2011) Conventional and Molecular Breeding Approaches for Seed Oil and Seed Protein Content Improvement in Cotton. International Research Journal of Plant Science, 2: 37-45.

Blasingame, D. and Patel, M.V. (2013). Cotton disease loss estimate committee report. Proc. Beltwide Cotton Conf., San Antonio, TX. 7-10. National Cotton Council of America, Memphis, TN. 1242-1246.

Bolek, Y., El-Zik K., Pepper, A.E., Bell, A.A., Magill, C.W., Thaxton, P.M. and Reddy, U.K. (2005). Mapping of Verticillium wilt resistance genes in cotton. Plant Science, 168: 1581-1590.

Cai, Y.F., He, X.H., Mo, J.C., Sun ,Q., Yang J.P. and Liu, J.G. (2009). Molecular research and genetic engineering of resistance to Verticillium wilt in cotton. African Journal of Biotechnology. 8: 7363-7372.

Cao,Z., Wang, P., Zhu, X., Chen, H. and Zhang, T. (2014). SSR Marker-Assisted Improvement of Fiber Qualities in Gossypium hirsutum Using $G$. barbadense Introgression Lines. TAG:
Theoretical and Applied Genetics, 127: 587-594.

Cobb, J.N., Biswa, P.S. and Platten, J.D. (2019). Back to the future: revisiting MAS as a tool for modern plant breeding. Theoretical and Applied Genetics, 132: 647-667.

Collard, B.C. and Mackill, D.J.( 2008). Marker-assisted selection: an approach for precision plant breeding in the twenty-first century. Philosophical Transactions of The Royal Society $B$ Biological Sciences. 363: 557-72.

Colyer, P.D. (2007). Current status of Fusarium wilt in the United States and future challenges. Proc. World Cotton Research Conference. International Cotton Advisory Committee (ICAC).

Davey , J.W., Hohenlohe, P.A., Etter, P.D., Boone, J.Q., Catchen, J.M. and Blaxter. (2011). Genome-wide genetic marker discovery and genotyping using nextgeneration sequencing. Nature Reviews Genetics, 12(7) : 499-510.

Du,X., Sun,J., Pan,Z., Zhou,Z., Pang,B. and Liu,G.Q. (2006), Chinese Academy of Agricultrual Science Anyang: Beltwide Cotton Conferences, San Antonio, Texas.

Fang, H., Zhou, H., Sanogo ,S., Lipka, A., Fang, D., Percy, R., Hughs, S., Jones,D., Gore, M. and Zhang, J. (2014) Quantitative trait locus analysis of Verticillium wilt resistance in an introgressed recombinant inbred population of Upland cotton. Molecular Breeding: New Strategies in Plant Improvement. 33: 709-720.

Fang, H., Zhou, H.P., Sanogo, S., Flynn, R., Percy, R.G., Hughs, S.E., Ulloa, M., Jones, D.C. and Zhang, J.F. (2013). Quantitative trait locus mapping for Verticillium wilt resistance in a backcross inbred line population of cotton (Gossypium hirsutum ×Gossypium barbadense) based on RGA-AFLP analysis. Euphytica- International 
Journal of Plant Breeding, 194: 79-91.

Freire, E.C., Morello, C.L., Farias, F.J.C., Silva Filho, J.L., Vidal Neto, F.C., Pedroza, M.B., Suinaga, F.A., Costa, J.N. and Andrade, F.P. (2008) O Agronegócio do algodão no Brasil. In: Beltrão, N.E.M. and Azevedo, D.M.P., Eds., Obje-tivos e métodos usados nos programas de melhoramento do algodão, Brasília, 299323.

Gallagher, J.P., Grover, C.E., Rex, K., Moran, M., Wendel, J.F. (2017). A New Species of Cotton from Wake Atoll, Gossypium stephensii (Malvaceae). Journal of Systematic Botany, 42: 115-123.

Gao, Y.Q., Nie, Y.C. and Zhang, X.L. (2003). QTL mapping of genes resistant to Verticillium wilt in Cotton. Science Journal. 15: 73-78.

Gaspar,Y.M., McKenna,J.A., McGinness, B.S., Hinch,J., Poon,S., Connelly, A.A., Anderson, M.A. and Heath, R.L. (2014). Field resistance to Fusarium oxysporum and Verticillium dahliae in transgenic cotton expressing the plant defensin $\mathrm{NaD} 1$. Journal of Experimental Botany, 65, 6: 1541-1550.

Gore, M., Percy, R..G., Percy, J.F., Zhang, Fang, D.D. and Cantrell, R.G. (2012). Registration of the TM-1/NM24016 cotton recombinant inbred mapping population. Journal of Plant Registrations. 6(1):124.

Grover, C.E., Zhu, X., Grupp, K.K., Jareczek, J.J., Gallagher, J.P., Szadkowski, E., Seijo, J.G., Wendel, J.F. (2015) Molecular confirmation of species status for the allopolyploid cotton species, Gossypium ekmanianum Wittmack. Genetic Resources and Crop Evolution., 62: 103-114.

GUO, Xiu-hua, CAI, Cai-ping, YUAN, Dong-dong, ZHAN, Gren-shan, XI Jinglong and GUO, Wang-zhen (2016).Development and identification of Verticillium wilt-resistant upland cotton accessions by pyramiding QTL related to resistance. Journal of Integrative Agriculture 15(3): 512-520.

Guo, Q., Li, S., Lu, X., Gao, H., Wang, X., Ma, Y., Zhang, X., Wang, P., (2015) f. sp. vasinfectum on cotton in China. Institute of Plant Protection, Hebei Academy of Agricultural and Forestry Science, 99: 1569-1577.

Gutiérrez,O.A., Stelly, D.M., Saha, S., Jenkins, J.N., McCarty, Jr., Raska ,D.A. and Scheffler, B.E. (2009) Inte- grative Placement and Orientation of NonRedundant SSR Loci in Cotton Linkage Groups by Deficiency Analysis. Molecular Breeding, 23: 693-707.

Hadrys, H., Balick, M. and Schierwater, B.(1992), Yale University, Department of Biology Molecular Ecology, 1: 55-63.

Ince, A.G., Karaca, M. and Onus, A.N. CAPS-microsatellites: use of CAPS method to convert non-polymorphic microsatellites into useful markers. Molecular Breeding. (2010). 25(3): 491499.

Jian ,G., Ma C., Zheng, and Zou, Y. (2003). Advances in cotton breeding for resistance to Fusarium and Verticillium wilt in the last fifty years in China. Agricultural Science of China 36: 280288.

Jiang, F., Zhao, J., Zhou L., Guo, W.Z. and Zhang, T.Z. (2009). Molecular mapping of Verticillium wilt resistance QTL clustered on chromosomes D7 and D9 in upland cotton. Science China-Life Sciences, 52: 872-884.

Kantety, R.V., La- Rota, M., Matthews, D. E. and Sorrells, M. E. (2002).Data mining for simple sequence repeats in expressed sequence tags from barley, maize, rice, sorghum and wheat Plant Molecular Biology 48(5-6): 501-510.

Kirkby, K.A., Lonergan, P.A. and Allen, S.J. (2013). Three decades of cotton disease surveys in NSW, Australia. Journal of 
Crop and Pasture Science. 64:774-779.

Li, C.Q., Liu, G.S., Zhao, H.H., Wang, L.J., Zhang, X.F., Liu, Y., Zhou, W.Y., Yang, L.L., Li, P.B. and Wang ,Q.L. (2013). Marker-assisted selection of Verticillium wilt resistance in progeny populations of upland cotton derived from mass selection-mass crossing. EuphyticaInternational Journal of Plant Breeding, 191: 469-480.

Li, T., Ma, X., Li, N., Zhou, L., Liu ,Z., Han, H., Gui, Y., Bao, Y., Chen, J., and Dai, X. (2017). Genome-wide association study discovered candidate genes of Verticillium wilt resistance in upland cotton (Gossypium hirsutum L.). Plant Biotechnology Journal, 15(12), 15201532.

Liang, Q.Z., Hu, C., Hua, H., Li, Z. and Hua, J. (2013) Construction of a Linkage Map and QTL Mapping for Fiber Quality Traits in Upland Cotton (Gossypium hirsutum L.). Chinese Science Bulletin, 58: 3233-3243.

Limborska, S.A., Prosnyak, M.I., Bocharova, T.N. (1999). The Properties of Human DNA Fingerprints Produced by Polymeric Monocore Probes (PMC Probes), Genetic Analysis. 15: 19-24.

Lopez-Lavalle, L.A.B., McFadden, H. and Brubaker, C.L. (2007): Theoretical and Applied Genetics 115: 477-488.

Ma, C. and G.L., Jian. (1994). New cotton variety 866 resistant to Verticillium and Fusarium wilt with high yield and good fibre quality. (In Chinese with English abstract.) 27:88-88.

Miles, C. and Wayne, M. (2008)."Quantitative trait locus (QTL) analysis". Scitable by Nature Education. Population and Quantitative Genetics.

Myers, G.O., Jiang, B., Akash, M.W., Badigannavar, A. and Saha, S. (2009). Chromosomal Assignment of AFLP Markers in Upland Cotton (Gossypium hirsutum L.). Euphytica- International
Journal of Plant Breeding, 165: 391-399. Ning, Z.Y., Zhao, R., Chen, H., Ai, N.J., Zhang, X., Zhao,J., Mei, H.X., Wang, P., Guo,W.Z. and Zhang, T.Z. (2013). Molecular tagging of a major quantitative trait locus for broadspectrum resistance to Verticillium Wilt in Upland cotton cultivar Prema., 53: 2304-2312.

Niu, C., Lu,Y.Z., Yuan,Y.L., Percy,R.G., Ulloa,M. and Zhang,J.F.(2011). Mapping resistance gene analogs (RGAs) in cultivated tetraploid cotton using RGAAFLP analysis. Euphytica- International Journal of Plant Breeding. 181:65-76.

O'Neill, N.R., Bailey,B.A. and Van-Berkum P.B. (1998). AFLP, a novel PCR-based DNA analysis technique, revealslevels of genomic variation within species of Colletotri-chum, Fusarium and Dendryphion. In: Abstracts $7^{\text {th }}$ International Congress of Plant Pathology, No. 2.2.87 (abstract).

Olson, M., Hood, L., Cantor,C.and Botstein, D. A common language for physical mapping of the human genome. (1989) Science.; 245(4925):1434-5

Palanga, K.K., Jamshed, M., Md., Harun or Rashid Gong, J., Li, J., Iqbal, M.S., Liu, A., Shang, H., Shi, Y., Chen, T., Ge, Q., Zhang,Z., Dilnur,

T., Li,W., Li,P., Gong, W.and Yuan Y. (2017): Quantitative Trait Locus Mapping for Verticillium wilt Resistance in an Upland Cotton Recombinant Inbred Line Using SNP-Based High Density Genetic Map. Journal of Frontiers in Plant Science. 8: 382.

Pang, M., Percy, R.G., Hughs, E. and Zhang, J. (2009). Promoter Anchored Amplified Polymorphism Based on Random Amplified Polymorphic DNA (PAAPRAPD) in Cotton. EuphyticaInternational Journal of Plant Breeding, 167: 281-291.

Rakshit, A., Rakshit, S., Singh, J., Chopra, 
S.K., Balyan, H.S., Gupta, P.K. and Bhat S.R. (2010). Association of AFLP and SSR Markers with Agronomic and Fibre Quality Traits in Gossypium hirsutum L. Journal of Genetics, 89: 155162.

Sal'kova, E.G. and Guseva ,N.N. (1965). The role of pectolytic enzymes of the Verticillium dahliae fungus in the development of cotton wilt. Dokl Akad Nauk SSSR, 163: 515-522.

Shao, B.X., Zhao,Y.L., Chen, W., Wang, H.M., Guo,Z.J.,Gong, H.Y., Sang, X.H., Cui, Y.L., and Wang, C.H. (2015).Analysis of upland cotton (Gossypium hirsutum) response to Verticillium dahliae inoculation by transcriptome sequencing. Journal of Genetics and Molecular Research 14 (4): 13120-13130.

Shen, Q.Y. and Q.Y. Chen. (1982). Advances in research on cotton wilt diseases in China. (In Chinese with English abstract.) Scientia Agricola Sinica. 15:17.

Shen, X., Guo, W., Lu, Q., Zhu, X., Yuan, Y. and Zhang, T. (2007) Genetic Mapping of Quantitative Trait Loci for Fiber Quality and Yield Trait by RIL Approach in Upland Cotton. EuphyticaInternational Journal of Plant Breeding 155: 371-380.

Song, X. and Zhang, T. (2009) Quantitative Trait Loci Controlling Plant Architectural Traits in Cotton. Plant Science, 177: 317-323.

Tan, L.W. (1982). Progress in breeding for resistance to Fusarium and Verticillium wilts of cotton in China. (In Chinese with English abstract.) Journal of Scientia Agricultura Sinica 15(3):16-22.

Ulloa, M., Hutmacher, R.B., Davis, R.M., Wright, S.D., Percy, R. and Marsh, B. (2006): Breeding for Fusarium Wilt Race 4 Resistance in Cotton under Field and Greenhouse Conditions. The Journal of Cotton Science. 10: 114-127.

Ulloa, M., Hutmacher, R.B., Roberts, P.A., Wright, S.D., Nichols, R.L. and Davis, R.M., (2013): Inheritance and QTL mapping of Fusarium wilt race 4 resistance in cotton. Journal of Theoretical and Applied Genetics, Cropping Systems Research Laboratory, Plant Stress and Germplasm Development Research 126(5): 14051418.

Ulloa, M., Wang, C., Hutmacher, R.B., Wright, S.D., Davis, R.M., Saski, C.A. and Roberts, P.A. (2011): Mapping Fusarium wilt race 1 resistance genes in cotton by inheritance, QTL and sequencing composition. Journal of Molecular Genetics and Genomics. 286:21.

Varshney, R. K., Graner, A. and Sorrells, M. E. (2005). Journal of Trends in Biotechnology. 23(1): 48-55

Wang ,L.H. and Dai, X.F. (2003): Progress on Molecular Research of Cotton Verticillium wilt resistances. Biotechnology Research Institute, Chinese Academy of Agricultural Sciences. 1(1): 97-102.

Wang, C. and Roberts, P.A. (2006): A Fusarium Wilt Resistance Gene in Gossypium barbadense and Its Effect on Root-Knot Nematode-Wilt Disease Complex. The American Phytopathological Society 96: 727-734.

Wang, F., Liu, R., Wang, L., Zhang,C., Liu,G., Liu, Q., Ma, X. and Zhang, J. (2018): Molecular Markers of Verticillium Wilt Resistance in Upland Cotton (Gossypium hirsutum L.) Cultivar and Their Effects on Assisted Phenotypic Selection. Euphytica- International journal on theoretical and applied aspects of plant breeding. 19: 424-430.

Wang, H.M., Lin, Z.X., Zhang, X.L., Chen, W., Guo, X.P., Nie, Y.C. and Li, Y.H. (2008). Mapping and quantitative trait 
loci analysis of Verticillium wilt resistance genes in cotton. Journal of Integrative Plant Biology. 50: 174-182.

Wang, Q., Fang, L., Chen, J., Hu, Y., Si, Z., Wang, S., Chang, L., Guo, W. and Zhang, T. (2015) Genome-Wide Mining, Characterization, and Development of Microsatellite Markers in Gossypium Species. Science. Repository, State Key Laboratory of Crop Genetics and Germplasm Enhancement

Wang, X., Ma, J., Yang, S., Zhang, G. and Ma, Z. (2007): Assessment of genetic diversity among Chinese upland cottons with Fusarium and/or Verticillium wilts resistance by AFLP and SSR markers. Frontiers of Agriculture in China. 1(2): 129-135.

Wendel, J.F. and Cronn, R.C. (2003). Polyploidy and the evolutionary history of cotton. Part of the Botany Commons, Genetics Commons, and the Plant Breeding and Genetics Commons. 78: 139-186.

Wendel, J.F., Brubaker, C.L. and Percival, A.E. (1992). Genetic diversity in Gossypium hirsutum and the origin of Upland cotton. Genetic Diversity in Plants. 79: 1291-1310.

Williams, J.G.K., Kubelik, A.R., Livak, K.J., Rafalski, J.A. and Tingey, S.V. (1990). Nucleic Acid Research, 18: 6531-6535. Central Research and Development Department, E.I. du Pont de Nemours \& Co., Inc, Wilmington, $D E$

Wilson, I.W., Lopez-Lavalle, L.A.B., Gillespie, V.J., Tate, W.A., Ellis, M.H., Stiller, W.N. and Llewellyn,D.L. (2012): Molecular mapping of a new source of Fusarium wilt resistance in tetraploid cotton (Gossypium hirsutum L.). A Repository of Agricultural Research Outputs Molecular Breeding. 30: 11811191.

WU, Yao ting, Zhang, Tian zhen and Yin, Jian mei. (2001.) Genetic diversity detected by DNA markers and phenotype in upland cotton. Journal of Genetics and Genomics. Cotton Research Institute, Key Laboratory for Crop Genetics and Germplasm Enhancement.

Yang, C., Guo, W.Z., Li, G.Y., Gao, F., Lin, S.S. and Zhang, T.Z. (2008). QTLs mapping for Verticillium wilt resistance at seedling and maturity stages for in G. barbadense L. Plant Science Journal. 174: 290-298.

Zhang, J., Fanga, H., Zhou, H., Sanogo, S. and Ma, Z. (2015): Genetics, Breeding, and Marker-Assisted Selection for Verticillium Wilt Resistance in Cotton. Crop Science Society of America. 54: 1289-1303.

Zhang, J., Sanogo, S., Ma, Z., and Qu, Y. (2015): Breeding, Genetics, and Quantitative Trait Locus Mapping for Fusarium Wilt Resistance in Cotton. Crop Science Society of America, 55.

Zhang, J., Yu, J., Pei, W., Li, X., Said, J., Song, M. and Sanogo, S. (2015): Genetic analysis of Verticillium wilt resistance in a backcross inbred line population and a meta-analysis of quantitative trait loci for disease resistance in cotton. $B M C$ Genomics, US National library of Medicine, National Institute of Health. 16: 577.

Zhang, J.F., Fang, H., Zhou, H.P., Sanogo, S. and Ma, Z.Y. (2014). Genetics, breeding, and marker-assisted selection for Verticillium wilt resistance in cotton. Crop Science society of America. 54: 1289-1303.

Zhang, X., Yuan, Y., Wei, Z., Guo, X., Guo, Y., Zhang, S., Zhao, J., Zhang, G., Song, X. and Sun, X. (2014). Molecular mapping and validation of a major QTL conferring resistance to a defoliating isolate of Verticillium wilt in cotton (Gossypium hirsutum L.). Public Library of Science ONE. 9: 96226.

Zhang, Z.S., Xiao, Y.H., Luo, M., Li, X.B., 
Luo, X.Y., Hou, L., Li, D.M. and Pei, Y. (2005) Construction of a Genetic Linkage Map and QTL Analysis of Fiber-Related Traits in Upland Cotton (Gossypium hirsutum L.). Euphytica, International Journal of Plant Breeding. 144: 91-99.

Zhao, Y., Wang, H., Chen, W. and Li, Y. (2014) Genetic Structure, Linkage Disequilibrium and Association Mapping of Verticillium Wilt Resistance in Elite Cotton (Gossypium hirsutum L.) Germplasm Population. Public Library of Sience ONE. 9: 1-15.

Constable, G.A. \& Bange, Michael. (2015). The yield potential of cotton (Gossypium hirsutum L.). Field Crops Research. 182. 10.1016/j.fcr.2015.07.017.

Khan M.A. et al., (2020) World Cotton Production and Consumption: An Overview. In: Ahmad S., Hasanuzzaman M. (eds) Cotton Production and Uses. Springer, Singapore

Zhao XP, Si Y, Hanson RE, et al., Dispersed repetitive DNA has spread to new genomes since polyploid formation in cotton [published correction appears in Genome Res 1998 Jun;8 (6):682]. Genome Res. 1998;8(5):479492. doi:10.1101/gr.8.5.479

Zhang Q, Gao X, Ren Y, Ding X, Qiu J, Li N, Zeng $F$ and Chu $Z$ (2018). Improvement of Verticillium Wilt Resistance by
Applying Arbuscular Mycorrhizal Fungi to a Cotton Variety with High Symbiotic Efficiency under Field Conditions. Int. J. Mol. Sci., 19(1), 241

GUO Xiu-hua, CAI Cai-ping, YUAN Dongdong, ZHANG Ren-shan, XI Jing-long, GUO Wang-zhen (2015). Development and identification of Verticillium wiltresistant upland cotton accessions by pyramiding QTL related to resistance. Journal of Integrative Agriculture. 1-15. Doi : 10.1016/S2095-3119(15)61083-8.

Majeed S, Rana IA and Atif RM. Role of SNPs in determining QTLs for major traits in cotton. J. Cotton Res. 2(5). https://doi.org/10.1186/s42397-0190022-5

Ditta A, Zhou Z, Cai X, et al., Assessment of Genetic Diversity, Population Structure, and Evolutionary Relationship of Uncharacterized Genes in a Novel Germplasm Collection of Diploid and Allotetraploid Gossypium Accessions Using EST and Genomic SSR Markers. Int J Mol Sci. 2018;19(8):2401. Published 2018 Aug 14. doi:10.3390/ijms19082401

Wan $\mathrm{P}$, Huang $\mathrm{Y}$, Wu $\mathrm{H}$, et al., Increased frequency of pink bollworm resistance to Bt toxin CrylAc in China. PLoS One. 2012;7(1):e29975.

doi:10.1371/journal.pone.0029975

\section{How to cite this article:}

Aman Deep Ranga, Vasudha Kak and Mayur S. Darvhankar. 2020. Genetic and Molecular Research of Resistance to Wilt in Cotton: A Concise Review. Int.J.Curr.Microbiol.App.Sci. 9(06): 2410-2422. doi: https://doi.org/10.20546/ijcmas.2020.906.296 